American J. of Engineering and Applied Sciences 2 (3): 544-558, 2009

ISSN 1941-7020

(C) 2009 Science Publications

\title{
Prediction of Seismic Active Earth Pressure Using Curved Failure Surface with Localized Strain
}

\author{
Hemanta Hazarika \\ Department of Architecture and Environment Systems, Akita Prefectural University, \\ 84-4, Tsuchiya, Ebinokuchi, Yurihonjo 015-0055, Akita, Japan
}

\begin{abstract}
Problem statement: Correct evaluation of the earth pressure against retaining structure during earthquake is essential for the safe and economic design of geotechnical structures. Progressive deformation in the backfill and the assumed shape of failure wedge affect the calculated values of seismic earth pressures. However, no research until now is available that considers both of these two factors in an analysis. Approach: In this study, a new analytical methodology was proposed that took into the account the progressive failure of the backfill soil as well as the shape of the failure wedge. A new formulation was first established taking the failure plane as the combination of a curved lower part and a straight upper part. The localized deformation of the backfill was accounted for in the formulation by utilizing the mobilized friction angle and the peak friction angle depending on the locations along the failure surface. The proposed methodology was validated by comparing the calculated results with the established experimental results. Calculations were also performed for different types of wall with various backfill inclinations. Results: The developed methodology could predict the seismic active earth pressure against retaining structure with reasonable accuracy. It could also realistically predict the active failure domain in the backfill soil at the high excitation level, as compared to the pseudo-static solution provided by the well-known Mononobe-Okabe method. Conclusion/Recommendations: It was observed that the Mononobe-Okabe method underestimates the seismic active earth pressure and overestimates the domain of failure zone in the backfill, especially under intense seismic excitation. The proposed methodology, therefore, can contribute greatly towards the economic earthquake resistant design of geotechnical structures.
\end{abstract}

Key words: Localized deformation, log-spiral method, Mononobe-Okabe theory, retaining structure, seismic active earth pressure

\section{INTRODUCTION}

Damage to retaining structures is common in almost every major historical earthquake. Most of the reported damage during devastating earthquakes is due to the increased lateral pressures, which in turn leads to sliding, overturning and tilting of structures ${ }^{[1]}$. In the 1995 Hyogoken-Nambu earthquake, Kobe, Japan (Kobe Earthquake), many gravity-type retaining structures suffered huge damage ${ }^{[2-4]}$. As a matter of fact, the damage suffered by many retaining structures during the 1923 Kanto earthquake, Japan gave birth to the well-known Mononobe-Okabe method, which has been used extensively in design offices for the seismic analysis and design all over the world ${ }^{[5,6]}$. A great deal of research ${ }^{[7-18]}$ have been performed since the advancement of the Mononobe-Okabe theory (referred hereafter as the $\mathrm{M}-\mathrm{O}$ method) to evaluate its accuracy. A good summary of the M-O method and the limitations of its application have been discussed in Ebeling and Morrison ${ }^{[19]}$.
The 1995 Hyogoken-Nanbu earthquake brought devastating damage to more than $90 \%$ of the waterfront retaining structures, most of which were caisson type quay walls. Displacements of the quay walls during the earthquake were among the largest recorded in the history of port facilities in Japan. The design seismic coefficients of the structures were ranging from 0.10 0.25. Variations in these coefficients reflect the difference in the site conditions and the level of safety specified according to the importance as stipulated in the design standard of the then Ministry of Transport, Japan $^{[20]}$. Structures that were designed using seismic coefficient of $0.10-0.15$ suffered excessive damage. Similar damage resulting from the use of low seismic coefficient was also reported in a moderate level earthquake (2005 West off Fukuoka Prefecture earthquake) that occurred in the western part of Fukuoka, Japan. Damage to port facilities during that earthquake has been summarized in Sugano et al. ${ }^{[21]}$. Most of the reported damage during the Hyogo-ken Nanbu earthquake was attributed either to the soil 
failures due to liquefaction or to the structural failures due to strong inertia force. Towhata et al. ${ }^{[22]}$ recognized that the effect of the increased or decreased lateral earth pressure during the earthquake prior to and/or after liquefaction might have been another cause of devastation to retaining structures during that earthquake. This has raised concern regarding the applicability of the $\mathrm{M}-\mathrm{O}$ method to intense ground motions such as those during the Hyogoken-Nanbu earthquake.

Ostadan $^{[23]}$ has described the M-O method as the most abused methods in the geotechnical engineering practice. Field observations and experimental data have shown that hardly any of the assumptions used in the development of the $\mathrm{M}-\mathrm{O}$ method are applicable for building walls. The new understanding, in fact, prompted the Nuclear Regulatory Commission (NRC) of the United States to reject the M-O method as well as the other methods based on the $\mathrm{M}-\mathrm{O}$ method for application to critical structures. Amid growing criticism centering the $\mathrm{M}-\mathrm{O}$ method, an emerging trend in recent years is to modify the method ${ }^{[24]}$ in the design of geotechnical structures.

Leaving aside the problems arising out of the design and applications of the M-O method, the underlying theory itself suffers from several limitations (as described below), especially under intense ground motions. The first and foremost is the pseudo-static nature of the theory. It is, however, sometimes possible to alleviate such shortcoming by using a time-stepping analysis of the earthquake motion ${ }^{[18]}$. The second shortcoming of the M-O theory is that it can predict the total earth pressure only under moderate earthquake ground motions. Under intense ground motions, the theory predicts unrealistically low values of seismic earth pressure.

The third drawback (a major drawback) of the M-O theory is the inherent assumption stemming directly from the Coulomb earth pressure theory on which the method is based. That is, the formation of the failure plane in the backfill is instantaneous with simultaneous mobilization of the friction angle, $\phi$ along the failure plane. The shear resistance, $\phi$ is assumed to be uniform, isotropic and constant in the M-O method. This, however, is not the case in the actual situation. Attainment of the active or the passive state (plastic equilibrium state), involves progressive deformation of the backfill. Progressive deformation and strain localization are two phenomena, which are delicately intertwined. The behavior of the sliding soil mass, thus, will be governed by the strength anisotropy, progressive failure and strain localization. Koseki et al. ${ }^{[25]}$ proposed a modified pseudo-static limit equilibrium based graphical procedure, where the effect of strain localization in the backfill soil and the associated postpeak reduction of the friction angle were taken into the account. Zhang and $\mathrm{Li}^{[26]}$, adopted a similar approach and mathematically evaluated the effect of strain localization on the M-O method.

The fourth drawback (another major drawback) of the M-O theory is that it assumes the rupture surface of the failure wedge as a planar one. However, in reality, the rupture surface is not a planar one and can be closely approximated by a curved lower part and a straight upper part. Assumed shape of the failure surface affects the magnitude of seismic earth pressure. It has been observed that the calculated active coefficient for static earth pressure using curved surface does not differ significantly from the planar surface assumption. The same, however, cannot be true for the calculation of active thrust under seismic load, where the inertial forces enter into the governing differential equations. Centrifuge tests results of Nakamura ${ }^{[27]}$ in fact have clearly displayed the curved nature of failure surface under dynamic loading and it was concluded that the hypothetical conditions of the $\mathrm{M}-\mathrm{O}$ method do not appropriately express the real behavior of backfill and gravity retaining walls during earthquakes. The effect of the inertial forces was taken into the consideration in the modified version of the M-O method proposed by Fang and Chen ${ }^{[28]}$, where it was emphasized the need for careful consideration while using the M-O method for calculating the seismic earth pressures. A few other methods ${ }^{[29,30]}$ are available, where the effect of curved failure surface on the calculation of seismic earth pressures was taken into consideration.

Having recognized the drawbacks of the $\mathrm{M}-\mathrm{O}$ method, an emerging trend in recent years is to modify the $\mathrm{M}-\mathrm{O}$ method during an intense earthquake ground motion $^{[24]}$. Performance-Based Design (PBD) ${ }^{[31]}$, which is becoming he norm in the design of geotechnical structures as well, specifies the intense earthquake motion (Level 2 earthquake motion ${ }^{[3]}$ as the design ground motion for safety of a structure during or after an earthquake. Thus, the $\mathrm{M}-\mathrm{O}$ method is not suitable in the framework of PBD.

However, no research until now is available that considers both the progressive deformation in backfill as well as the shape of failure surface for analyzing seismic earth pressure against retaining wall. The objective of this research is to develop a new methodology, wherein, both are incorporated in a closed form analytical solution. A procedure is proposed here, for the prediction of seismic active earth pressure, by taking into account the progressive 
deformation of backfill as well as the curved shape of failure surface. In the following sections, a mathematical formulation is first established, in which the failure plane is taken as the combination of a curved lower part and a straight upper part. The curved part was assumed to be of a logarithmic spiral of convex shape. The Mohr stress circle under plastic equilibrium state of the backfill is drawn for the dynamic loading condition. Various geometrical parameters were determined using the Mohr stress circle. Progressive deformation states of the backfill were accounted for, by utilizing the peak friction angle $\left(\phi_{\text {peak }}\right)$ and the residual friction angle $\left(\phi_{\text {res }}\right)$, at different locations along the failure plane of the active wedge. Effectiveness of the proposed methodology is evaluated by comparing the calculated results with experimental results of other researchers.

Logarithmic spiral method for prediction of seismic active earth pressure: Experimental and theoretical investigations for validating the use of wedge theory of earth pressure have shown that the sliding surface that is formed in the backfill of a retaining structure is composed of a curved lower part and a planar upper part that corresponds to the Rankine state. The exact equation of the curved part has not yet been found-it is likely that the problem becomes indeterminate and a closed form solution becomes too complex to achieve. Therefore, in practice, the real curve is replaced by simple curves such as the circle or the logarithmic spiral. Curved failure plane approach for calculating the dynamic passive thrust against retaining structures was first proposed by Ichihara et $a l^{[32]}$. A kinematical approach of limit analysis theory was adopted by Soubra and Macuh ${ }^{[33]}$, where upper bound solutions for calculating the seismic active and passive earth pressures were given. On the other hand, Chang and Chen ${ }^{[29]}$ put forward an analytical solution based on the log-sandwich mechanism. A brief review of the approach described by Chang and Chen ${ }^{[29]}$ is made first, followed by the approach adopted in this research.

Log-sandwich mechanism of Chang and Chen ${ }^{[29]}$ : In this approach, a general soil-wall system with translational wall movement and a $\phi$-spiral logsandwich mechanism of failure proposed by Chen and Rosenfarb $^{[30]}$ was adopted. The underlying principles of the theoretical formulations are shown in Fig. 1. In the formulation, the variables involved are defined as the following:

$\mathrm{H}=$ Vertical height of wall

$\gamma=$ Unit weight of the backfill material $\phi=$ Angle of internal friction of the backfill material

$\mathrm{c}=$ Cohesion of the backfill material

$\delta=$ Angle of soil-wall interface friction

$\mathrm{k}=$ Seismic coefficient

$\theta=$ Inclination of the seismic coefficient with the horizontal

$q=$ Backfill surcharge

All the others such as the geometrical factors, $\alpha, \beta$, $\rho, \psi, \theta$ and the incremental displacement or velocities $v_{0}$, $v_{1}, v_{3}, v_{\theta}$ are as defined in Fig. 1. The method assumed that the shear strength of the soil is unaffected (implying no localized deformation in the backfill) as a result of the seismic loading. Also, a constant seismic coefficient was assumed for the entire soil mass involved in the interaction. The seismic active earth pressure was derived by considering the equilibrium of external work, $\sum[\Delta \mathrm{W}]_{\mathrm{ext}}$ and internal energy dissipation,

$\sum[\Delta \mathrm{D}]$. The incremental external work $(\Delta \mathrm{W})$ due to an external force is the external force multiplied by the corresponding incremental displacement or velocity. The incremental external work due to self-weight in a region is the vertical component of the velocity in that region multiplied by the weight of the region.

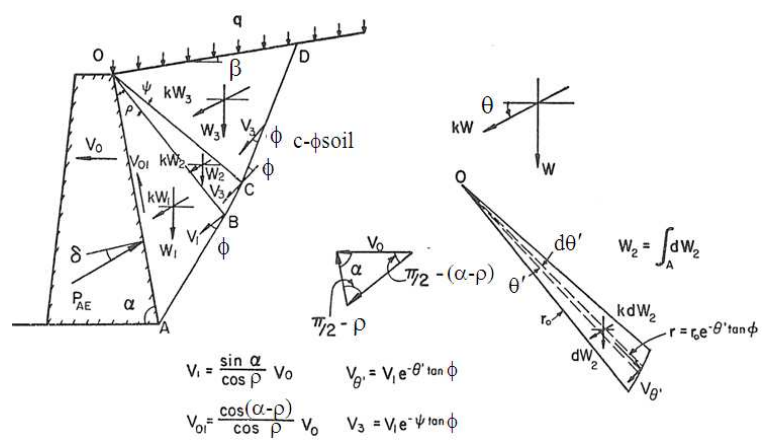

(a)

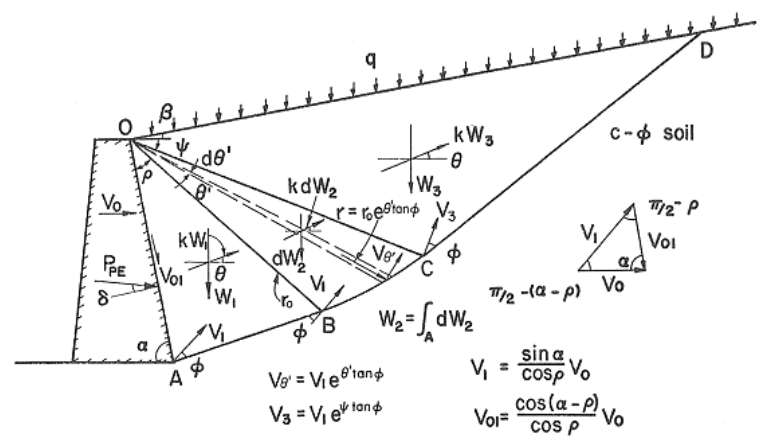

(b)

Fig. 1: Log-sandwich mechanism for seismic pressure analysis $^{[2]}$ 
The incremental energy dissipation $(\Delta \mathrm{D})$ is the total frictional force multiplied by the incremental displacement for the pure friction energy dissipation along the soil-wall interface. Thus, referring to Fig. 1:

$$
\begin{aligned}
& \sum[\Delta \mathrm{W}]_{e x t}=\Delta \mathrm{W}_{\mathrm{OAB}}+\Delta \mathrm{W}_{\mathrm{OBC}}+\Delta \mathrm{W}_{\mathrm{OCD}}+\Delta \mathrm{W}_{\mathrm{P}} \\
& \sum[\Delta \mathrm{D}]=\Delta \mathrm{D}_{\mathrm{OB}}+\Delta \mathrm{D}_{\mathrm{AB}}+\Delta \mathrm{D}_{\mathrm{BC}}+\Delta \mathrm{D}_{\mathrm{CD}}+\Delta \mathrm{D}_{\mathrm{OBC}}
\end{aligned}
$$

By equating $\sum[\Delta \mathrm{W}]_{\text {ext }}$ in Eq. 1 to $\sum[\Delta \mathrm{D}]$ in Eq. 2, the following equation for the active earth pressures during earthquakes $\left(\mathrm{P}_{\mathrm{AE}}\right)$ was obtained:

$$
\mathrm{P}_{\mathrm{AE}}=\frac{1}{2} \gamma \mathrm{H}^{2} \mathrm{~N}_{\mathrm{A \gamma}}+\mathrm{qHN}_{\mathrm{Aq}}+\mathrm{cHN}_{\mathrm{Ac}}
$$

In the above equation, $\mathrm{N}_{\mathrm{A} \gamma}, \mathrm{N}_{\mathrm{Aq}}$ and $\mathrm{N}_{\mathrm{Ac}}$ are the active earth pressure factors.

Log-sandwich mechanism is an upper bound technique of limit analysis using perfect plasticity theory, which can be applied for determining the seismic lateral earth pressure in a quasi-static manner. Thus, it is no different from the Mononobe-Okabe theory; a quasi-static solution of the actual soilstructure interaction problem. This, along with the assumption that the shear resistance within the entire failure mass is constant, may be the reason why the method by Chang and Chen ${ }^{[29]}$ failed to detect any differences in the results from the Mononobe-Okabe theory while calculating the active earth pressures. As has been already proved, in the case of static earth pressure, the calculated earth pressure coefficients using curved failure surface do not differ much from the classical solution by the Coulomb theory. However, when actual dynamic loading is considered (as opposed to the quasi-static loading), the differences will definitely surface. In addition, as pointed out by Uwabe and Moriya ${ }^{[34]}$, significant strain localization within backfill leads to increase in pressure, which has to be taken into consideration in an analytical formulation. Ignoring the strain localization of the backfill leads to underestimation of the developed pressure during earthquakes. As discussed in the previous section, analytical solution put forward by Koseki et al. ${ }^{[25]}$ has already proved such deficiency of the M-O method and ISO $^{[24]}$ has recommended to consider the effect of strain localization. The methodology presented below takes into the account the dynamic forces acting on the soil mass (bounded by the wall back face, ground surface and a curved failure surface) as well as the strain localization within the backfill.

\section{MATERIALS AND METHODS}

Log-spiral method: An inclined retaining wall of vertical height $\mathrm{H}$ with back face inclination $\alpha_{1}$ supporting a sandy backfill with surface inclination, $\beta$ and unit weight, $\gamma$ is shown in Fig. 2. The back face inclination $\alpha_{1}$ is considered positive for the configuration shown. According to the M-O theory, the seismic active thrust against the wall is given by the following equation:

$$
\mathrm{P}_{\mathrm{AE}}=\frac{1}{2} \gamma \mathrm{H}^{2}\left(1-\mathrm{k}_{\mathrm{v}}\right) \mathrm{K}_{\mathrm{AE}} / \cos \delta
$$

Here $\mathrm{K}_{\mathrm{AE}}$ is the horizontal coefficient of the seismic active earth pressure given by the following equation:

$$
\begin{aligned}
\mathrm{K}_{\mathrm{AE}}= & \frac{\cos ^{2}\left(\alpha_{1}+\theta_{0}-\phi\right) \cos \delta}{\cos \theta_{0} \cos ^{2} \alpha_{1} \cos \left(\alpha_{1}+\theta_{0}+\delta\right)} \\
& {\left[1+\sqrt{\frac{\sin (\phi+\delta) \sin \left(\phi-\beta-\theta_{0}\right)}{\cos \left(\alpha_{1}+\theta_{0}+\delta\right) \cos \left(\alpha_{1}+\beta\right)}}\right]^{2} }
\end{aligned}
$$

$\phi=$ The angle of internal friction (assumed uniform and isotropic)

$\delta=$ The friction angle at the interface between the retaining wall and the backfill soil

$\theta_{0}=$ The composite seismic angle defined in terms of $\mathrm{k}_{\mathrm{h}}$, the horizontal seismic coefficient

$\mathrm{k}_{\mathrm{v}}=$ The vertical seismic coefficient as follows:

$\tan \theta_{0}=\mathrm{k}_{\mathrm{h}} /\left(1-\mathrm{k}_{\mathrm{v}}\right)$

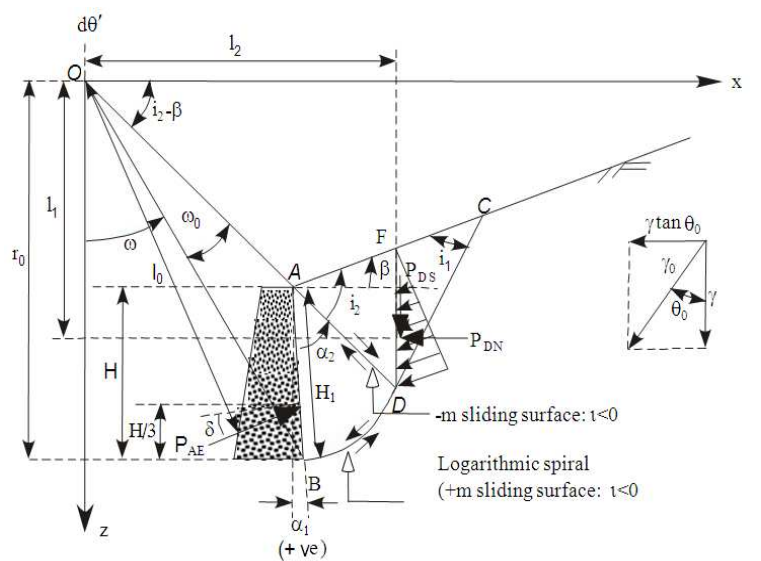

Fig. 2: Retaining wall backfill with composite sliding surface 
There is an upper limit of $\mathrm{k}_{\mathrm{h}}$ in the M-O method, beyond which the coefficient $\mathrm{K}_{\mathrm{AE}}$ in Eq. 4 cannot be evaluated when the term $\left(\phi-\beta-\theta_{0}\right)$ in the square term in Eq. 5 becomes negative. Beyond this limit equilibrium state, the pseudo-static equilibrium of forces cannot be maintained. This is one serious drawback of the M-O method apart from those, which have already been discussed in the previous section.

In this research, instead of a planar straight line surface as assumed in the above equation, the sliding surface $\mathrm{BC}$ is approximated to be composed of a logarithmic spiral BD (convex spiral) with its center at $\mathrm{O}$ and a straight line DC (Fig. 2). Within the soil mass $\mathrm{ADC}$, the state of stress is the same as the Rankine active pressure acting on the vertical section FD under earthquake $\left(\mathrm{P}_{\mathrm{DN}}\right.$ and $\left.\mathrm{P}_{\mathrm{DS}}\right)$ as shown. Considering the clockwise moments as negative, the straight line $\mathrm{AD}$ is $\mathrm{a}-\mathrm{m}$ sliding surface and $\mathrm{DC}$ is $\mathrm{a}+\mathrm{m}$ sliding surface.

It is to be noted that the sliding surface can be either convex or concave depending on the location of the center of the logarithmic spiral "O". In Fig. 2, the center "O", is located on the upper extreme of line AD resulting in a convex type of sliding surface. For a backfill with negative inclination $(\beta<0)$, the center "O" will lie in the lower extreme of the line $A D$ resulting in a concave surface. In this study, equations will be derived considering only the convex type surface. Nevertheless, the method can be extended easily for concave type failure surface (as observed in the experiments by Nakamura ${ }^{[27]}$ ) by changing a few geometrical parameters.

In Fig. 2, the straight line DC is tangent to the spiral $\mathrm{BD}$. The resultant reaction $\mathrm{R}$ along the logarithmic spiral BD passes through the center "O". Hence, the reaction $\mathrm{R}$ has no contribution towards the resulting moment and, therefore, was omitted from the derivation that follows (Eq. 7 and 8). Therefore, the moment of the active earth pressure during earthquake, $\mathrm{P}_{\mathrm{AE}}$, must be equal to the total moment of the gravity force of the soil mass $\mathrm{ABDF}$, the seismic force acting on the soil mass ABDF and the forces acting on the vertical section FD during earthquake. A number of assumptions listed below have been adopted while deriving the equations:

- The wall is rigid

- The inertial accelerations are constant throughout the soil body making it the same as the D'Alembert body forces acting in the opposite direction to the accelerations

- The interaction between the soil foundations and the structure at the base is ignored and therefore, the friction at the base of the structure assumed to play no role in the earth pressure calculation

- Vertical accelerations are zero $\left(\tan \theta_{0}=\mathrm{k}_{\mathrm{h}}\right.$ in Eq. 6)

- No surcharge acting on the top of the backfill

- The backfill is cohesionless $(c=0)$

Based on the above assumptions and applying D'Alembert's principle (the moment equilibrium of the failure wedge), renders the following equation:

$\mathrm{P}_{\mathrm{AE}} \mathrm{l}_{0}=-\mathrm{M}_{1}+\mathrm{M}_{2}+\mathrm{M}_{3}+\mathrm{M}_{4}$

Here:

$\mathrm{L}_{0}=$ Arm length of the resultant seismic active thrust

$\mathrm{P}_{\mathrm{AE}}, \mathrm{M}_{1}=$ Moment due to soil mass in the log-spiral zone $\mathrm{ABD}$ due to its body force including the horizontal seismic effect

$\mathrm{M}_{2} \quad=$ Moment of the soil mass ADF due to its body force including the horizontal seismic effect

$\mathrm{M}_{3} \quad=$ Moment of the active Rankine earth pressure including the seismic effect acting upon the vertical section FD

The clockwise moments are considered positive throughout the discussions that follow. Equation 7, can also be rewritten into a form given below:

$\mathrm{P}_{\mathrm{AE}} \mathrm{l}_{0}=-\mathrm{M}_{1}+\mathrm{M}_{2}+\mathrm{M}_{3}+\mathrm{M}_{4}$

In Eq. 8, $\left(M_{1}^{\prime}-M_{A}\right)$ represents the term $M_{1}$ of Eq. 7 which is the resultant moment due to actual soil mass ABD. Here $\mathrm{M}_{\mathrm{A}}=$ moment of the assumed soil mass of OBA due to its body force including the seismic effect, $M_{1}^{\prime}=$ moment of the assumed soil mass of the sector OBD due to its body force including the seismic effect. Thus, calculations of the moment $\mathrm{M}_{\mathrm{A}}$ due to nonexistent soil mass OBA is merely for mathematical conveniences and hence it contains a negative sign. Both the body forces (unit weight per length) and the seismic forces are considered in the evaluation of the moments $\mathrm{M}_{1}, \mathrm{M}_{2}$ and $\mathrm{M}_{3}$.

It is worthwhile mentioning here that the M-O method satisfies the conditions of force equilibrium $\left(\sum \mathrm{H}=0\right.$ and $\left.\sum \mathrm{V}=0\right)$ of the sliding mass. But it does not satisfy the boundary conditions in the Rankine region and of the wall and also does not satisfy the moment equilibrium. Thus, the method cannot take into consideration the soil-structure interaction during earthquake loading. Most of the damage during 
earthquakes are the results of the soil-structure interaction. On the other hand, the logarithmic spiral method presented here satisfies not only the moment equilibrium $(\Sigma \mathrm{M}=0)$ of the soil mass, but also the boundary conditions in the Rankine region. The rigorous method developed by Sokolovski ${ }^{[35]}$ is the best developed and rational solution so far in the field of analytical solutions of earth pressure, since that method satisfies all the three conditions of equilibrium $\left(\sum \mathrm{H}=\right.$ $\left.0, \sum \mathrm{V}=0\right)$ and $\left(\sum \mathrm{M}=0\right)$ of the sliding mass and the boundary conditions of the Rankine region and of the wall. An extension of the Sokolovski method to calculate the dynamic earth pressure has been described in Ichihara et al $^{[32]}$.

Calculation of moment $\mathbf{M}_{\mathbf{1}}$ : As stated above, the moment $\mathrm{M}_{1}$ can be calculated as $\left(\mathrm{M}_{1}^{\prime}-\mathrm{M}_{\mathrm{A}}\right)$.

The moment, $\mathrm{M}_{\mathrm{A}}$ due to the assumed soil mass OBA can be obtained as follows (Fig. 3):

$$
\mathrm{M}_{1}=\mathrm{S}_{\mathrm{OBA}}\left(\mathrm{x}_{\mathrm{G} 1} \mathrm{k}_{\mathrm{h}}+\mathrm{y}_{\mathrm{G} 1}\right)
$$

In Eq. 9 the weight is calculated based on the area of the triangle $\mathrm{OBA}\left(\mathrm{S}_{\mathrm{OBA}}\right)$. The area $\mathrm{S}_{\mathrm{OBA}}$ and its center of gravity $\left(\mathrm{x}_{\mathrm{GA}}, \mathrm{z}_{\mathrm{GA}}\right)$ can be obtained from simple geometry as follows:

$\mathrm{S}_{\mathrm{OBA}}=\frac{1}{2} \mathrm{O} \overline{\mathrm{A}} \mathrm{O} \overline{\mathrm{B}} \sin \omega_{0}$

$\mathrm{x}_{\mathrm{GA}}=\frac{1}{3}\left[\mathrm{O} \overline{\mathrm{A}} \cos \left(\mathrm{i}_{2}-\beta\right)+\mathrm{O} \overline{\mathrm{B}} \cos \left(\omega_{0}+\mathrm{i}_{2}-\beta\right)\right.$

$\mathrm{z}_{\mathrm{GA}}=\frac{1}{3}\left[\mathrm{OA} \sin \left(\mathrm{i}_{2}-\beta\right)+\mathrm{O} \overline{\mathrm{B}} \sin \left(\omega_{0}+\mathrm{i}_{2}-\beta\right)\right.$

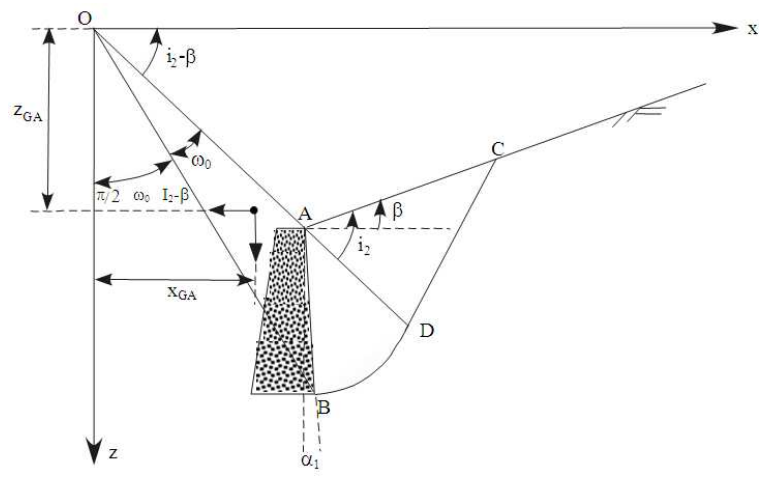

Fig. 3: Illustration of calculating the moment $\mathrm{M}_{\mathrm{A}}$
Pseudo-static calculation by the M-O method, assumes a linear increase of the horizontal seismic coefficient, $\mathrm{k}_{\mathrm{h}}$ with increasing maximum acceleration specifying it as a fraction of gravity. As a result, at intense earthquake motions (such as those in Level 2 motions), the calculated horizontal seismic coefficients increase rapidly. However, retaining structures will behave differently under Level 1 (L1) and Level 2 (L2) motions $^{[3]}$. Therefore, it is necessary to incorporate some correction factors to the value of $\mathrm{k}_{\mathrm{h}}$, under intense earthquake motions. Noda et al. ${ }^{[36]}$, based on the case histories of 129 damaged and undamaged gravity type quay walls in 12 different earthquakes found that such linear assumption overestimates the horizontal seismic coefficient values, especially at acceleration levels beyond $0.2 \mathrm{~g}$. In order to rectify the overestimation of the horizontal seismic coefficient, the following equations were proposed:

$$
\begin{array}{lll}
\tan \theta_{0}=\mathrm{k}_{\mathrm{h}}=\frac{\alpha_{\text {max }}}{\mathrm{g}}: & \alpha_{\text {max }}<0.2 \mathrm{~g} \\
\tan \theta_{0}=\mathrm{k}_{\mathrm{h}}=\frac{1}{3}\left(\frac{\alpha_{\max }}{\mathrm{g}}\right)^{\frac{1}{3}}: & \alpha_{\text {max }} \geq 0.2 \mathrm{~g}
\end{array}
$$

Where:

$\alpha_{\max }=$ The maximum value of the acceleration $\mathrm{g} \quad=$ The acceleration due to gravity

Matsuo and Itabashi ${ }^{[37]}$, on the other hand, based on the inverse analysis from the data of maximum ground acceleration of actual earthquakes, have proposed the following equation:

$$
\tan \theta_{0}=\mathrm{k}_{\mathrm{h}}=0.072+0.332 \frac{\alpha}{\mathrm{g}}
$$

Figure 4 compares the $\mathrm{M}-\mathrm{O}$ assumption together with the expressions given by Eq. 11 and 12 . It can be seen that, the equations proposed by Noda et al. ${ }^{[36]}$ result in decrease of the values of $k_{h}$ beyond $200 \mathrm{Gal}$ of acceleration. However, the equation proposed by Matsuo and Itabashi ${ }^{[37]}$ yields a decreasing tendency of the same beyond $100 \mathrm{Gal}$ of acceleration. The Japanese design standard ${ }^{[20]}$ uses Eq. 11a and b. However, in this study, the equation proposed by Matsuo and Itabashi ${ }^{[37]}$ was adopted.

The equation of the curved part (BD) of the sliding surface was taken as a logarithmic spiral (Fig. 2), which can be expressed in the form: 


$$
\mathrm{r}=\mathrm{r}_{0} \mathrm{e}^{-\omega \tan \phi}
$$

where, $\omega=$ The angle between $r$ from $r_{0}$, (considered positive if measured counterclockwise). The moment $\mathrm{M}_{1}^{\prime}$ can then be obtained as $\mathrm{M}_{1}^{\prime}=\mathrm{M}_{\mathrm{x}}+\mathrm{M}_{\mathrm{z}}$ where $M_{x}=\int z d A$ and $M_{z}=\int x d A$. It is worthwhile mentioning here that $\mathrm{M}_{\mathrm{x}}$ and $\mathrm{M}_{\mathrm{z}}$ are the static moments of inertia, in which the weights are calculated based on the area. $M_{x}$ and $\mathrm{M}_{\mathrm{z}}$ can be derived as follows:

$$
\begin{aligned}
& M_{y}=\frac{\frac{1}{3} r_{0}^{3} \tan \theta_{0}}{1+C_{1}^{2}}\left[e^{C_{1} \omega}\left(C_{1} \cos \omega+\sin \omega\right)\right]_{\omega_{1}}^{\omega_{2}} \\
& M_{x}=\frac{\frac{1}{3} r_{0}^{3}}{1+C_{1}{ }^{2}}\left[e^{C_{1} \omega}\left(C_{1} \sin \omega-\cos \omega\right)\right]_{\omega_{1}}^{\omega_{2}}
\end{aligned}
$$

In which, $\mathrm{C} 1=-3 \sin \phi$. The parameters $r_{0}, \omega_{1}$ and $\omega_{2}$ in Eq. 13 and 14 can be calculated using Fig. 2 from the following equations:

$\omega_{1}=\frac{\pi}{2}-\left(\omega_{0}+i_{2}-\beta\right)$

$\omega_{2}=\frac{\pi}{2}-\left(i_{2}-\beta\right)$

$\mathrm{r}_{0}=\frac{\cos \left(\beta-\mathrm{i}_{2}-\alpha_{1}\right)}{\sin \omega_{0}} \mathrm{H}_{1} \exp \left(\left(\frac{\pi}{2}-\left(\omega_{0}+\mathrm{i}_{2}-\beta\right)\right) \tan \varphi\right)$

Here $\mathrm{H}_{1}$ is the length of the back face of the wall, which is different from the vertical height $\mathrm{H}$ of the wall.

Calculation of moment $\mathbf{M}_{2}$ : The moment $\mathbf{M}_{2}$ can be calculated using Fig. 5 and is given by:

$$
\mathrm{M}_{3}=\mathrm{S}_{\mathrm{ADF}}\left(\mathrm{k}_{\mathrm{h}} \mathrm{x}_{\mathrm{G} 3}+\mathrm{y}_{\mathrm{G} 3}\right)
$$

where, $\left(\mathrm{x}_{\mathrm{G} 2}, \mathrm{y}_{\mathrm{G} 2}\right)$ is the center of gravity of $\triangle \mathrm{ADF}$ Fig. 5 and $\mathrm{S}_{\mathrm{ADF}}$ is the area of $\triangle \mathrm{ADF}$ and they can be derived as:

$$
\begin{aligned}
& \mathrm{S}_{\mathrm{ADF}}=\frac{1}{2} \mathrm{~A} \overline{\mathrm{D}}^{2} \frac{\cos \left(\mathrm{i}_{2}-\beta\right)}{\cos \beta} \sin \mathrm{i}_{2} \\
& \mathrm{x}_{\mathrm{G} 2}=\frac{1}{3}\left[(2 \mathrm{O} \overline{\mathrm{D}}+\mathrm{O} \overline{\mathrm{A}}) \cos \left(\mathrm{i}_{2}-\beta\right)\right] \\
& \mathrm{z}_{\mathrm{G} 2}=\frac{1}{3}\left[(2 \mathrm{O} \overline{\mathrm{D}}+\mathrm{O} \overline{\mathrm{A}}) \sin \left(\mathrm{i}_{2}-\beta\right)-\mathrm{F} \overline{\mathrm{D}}\right]
\end{aligned}
$$

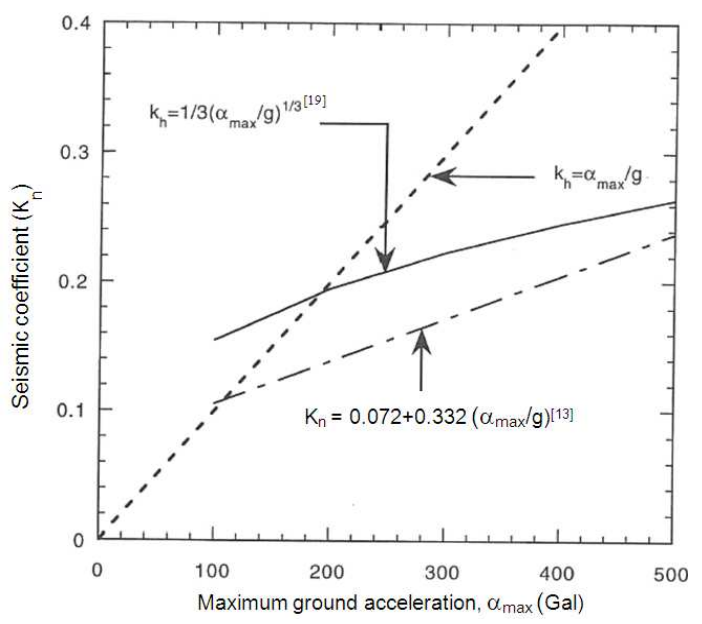

Fig. 4: Relation between seismic coefficient and maximum ground acceleration

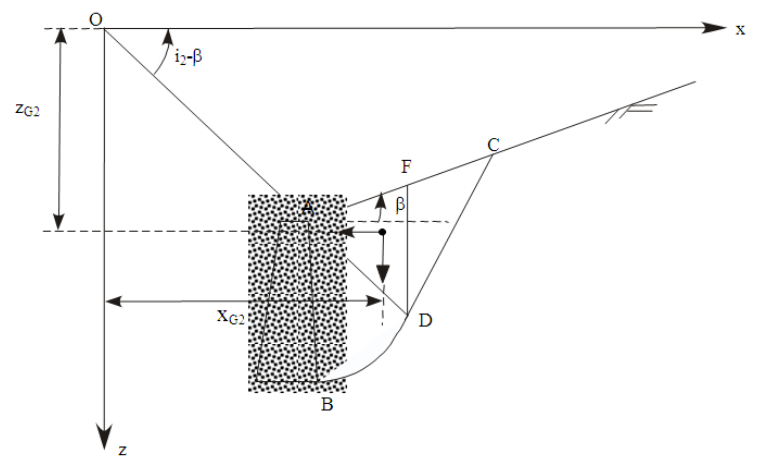

Fig. 5: Illustration of calculating the moment $\mathrm{M}_{2}$

Calculation of Moment $\mathbf{M}_{3}$ : The moment $\mathbf{M}_{3}$ is given by:

$\mathrm{M}_{4}=1_{1} \mathrm{P}_{\mathrm{DN}}+1_{2} \mathrm{P}_{\mathrm{DS}}$

The dynamic forces $\left(\mathrm{P}_{\mathrm{DN}}\right.$ and $\left.\mathrm{P}_{\mathrm{DS}}\right)$ acting on the soil mass in the active Rankine zone can be obtained using the Mohr circle for the active state during earthquake as shown in Fig. 6. Here, $l_{1}$ and $l_{2}$ are the arm lengths of the dynamic forces $P_{D N}$ and $P_{D S}$ respectively as illustrated in Fig. 2. In Fig. 6, P refers to the pole of the Mohr circle, $\mathrm{T}_{1}$ and $\mathrm{T}_{2}$ refers to the two rupture surfaces, $\varphi_{1}$ is the angle between the u-plane and the major principal plane. $\gamma_{0}$ is given by:

$$
\gamma_{0}=\gamma / \cos \theta_{0}
$$

The dynamic forces (considered positive in the direction shown in Fig. 2) can be obtained as follows: 


$$
\begin{aligned}
& \mathrm{P}_{\mathrm{DN}}=\frac{\gamma \overline{\mathrm{FD}}^{2} \cos \beta}{2 \cos ^{2} \phi \cos \theta_{0}}\left[1-\sin \phi \cos \left(\Delta_{0}+\theta_{0}-\beta\right)\right] \mathrm{C}_{2} \\
& \mathrm{P}_{\mathrm{DS}}=\frac{\gamma \overline{\mathrm{FD}}^{2} \cos \beta}{2 \cos ^{2} \phi \cos \theta_{0}} \sin \phi \sin \left(\Delta_{0}+\theta_{0}-\beta\right) \mathrm{C}_{2}
\end{aligned}
$$

Final expressions in Eq. 19 and 20 are derived by substituting the values of the normal stress $\left(\sigma_{\mathrm{x}}\right)$ and the shear stress $\left(\tau_{\mathrm{xz}}\right)$ obtained using the Mohr stress circle shown in Fig. 6. In these equations, $\mathrm{C}_{2}, \mathrm{C}_{3}$ and $\Delta_{0}$ are defined by using the expressions given below:

$$
\begin{aligned}
& \mathrm{C}_{2}=\frac{\cos \beta}{\cos ^{2} \varphi \cos \theta_{0}} \\
& \mathrm{C}_{2}=\cos \beta_{0}-\sqrt{\left(\cos ^{2} \beta_{0}-\cos ^{2} \phi\right)} \\
& \sin \Delta_{0}=\frac{\sin \beta_{0}}{\sin \phi} \\
& \beta_{0}=\beta+\theta_{0} \quad\left(\beta_{0} \leq \phi\right)
\end{aligned}
$$

Calculation procedures: The arm lengths $1_{0}, l_{1}$ and $l_{2}$ in Fig. 2 can be derived as following:

$$
\begin{aligned}
& 1_{0}=\overline{\mathrm{OB}} \sin \left(\delta+\omega_{0}+\mathrm{i}_{2}+\alpha_{1}-\beta\right)-\frac{1}{3} \mathrm{H}_{1} \cos \delta \\
& \mathrm{l}_{1}=\overline{\mathrm{OD}} \sin \left(\mathrm{i}_{2}-\beta\right)-\frac{1}{3} \overline{\mathrm{FD}} \\
& 1_{2}=\overline{\mathrm{OD}} \cos \left(\mathrm{i}_{2}-\beta\right)
\end{aligned}
$$

The angles $i_{1}, i_{2}$ (Fig. 2) can be obtained using the following equations:

$$
\begin{aligned}
& \mathrm{i}_{2}=\frac{\pi}{4}+\frac{\phi}{2}+\frac{\left(\beta_{0}+\Delta_{0}\right)}{2} \\
& \mathrm{i}_{2}=\frac{\pi}{4}+\frac{\phi}{2}+\frac{\left(\beta_{0}+\Delta_{0}\right)}{2}
\end{aligned}
$$

The angles $\mathrm{a}_{2}$ (Fig. 2) between the $\mathrm{z}$ axis and the m sliding surface AD can be obtained as follows:

$$
2 \alpha_{2}=\frac{\pi}{2}-\varphi+3 \beta+\Delta_{0}+\theta_{0}
$$

$\overline{\mathrm{OB}}, \overline{\mathrm{OD}}$ and $\overline{\mathrm{FD}}$, that appear in the above equations can be calculated from simple geometry as following:

$$
\overline{\mathrm{OB}}=\frac{\cos \left(\beta-\mathrm{i}_{2}-\alpha_{1}\right)}{\sin \omega_{0}}
$$

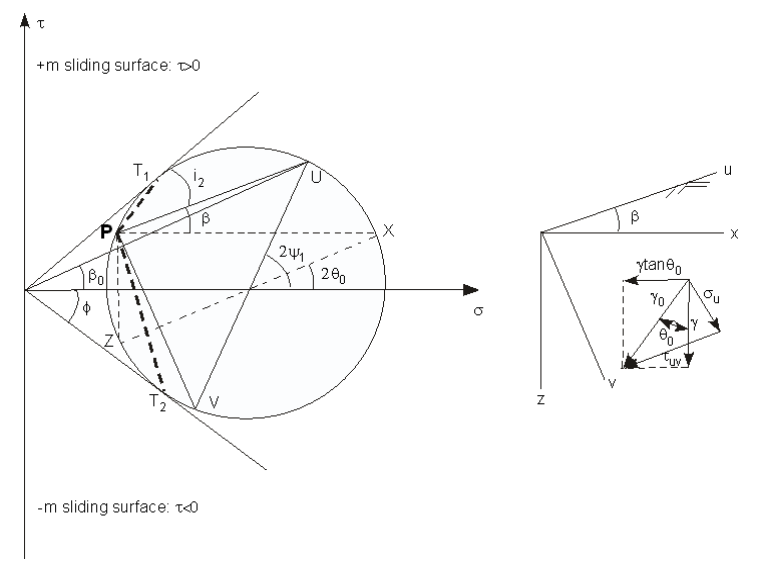

Fig. 6: Mohr's stress circle for seismic loading condition

$$
\begin{aligned}
\overline{\mathrm{OD}}= & \frac{\cos \left(\beta-\mathrm{i}_{2}-\alpha_{1}\right)}{\sin \omega_{0}} \mathrm{H}_{1} \exp \left(-\omega_{0} \tan \varphi\right) \\
\overline{\mathrm{FD}}= & \frac{\mathrm{H}_{1}}{\sin \omega_{0}} \frac{\sin \mathrm{i}_{2}}{\cos \beta}\left[\cos \left(\beta-\mathrm{i}_{2}-\alpha_{1}\right) \exp \right. \\
& \left.\left(-\omega_{0} \tan \varphi\right)-\cos \left(\omega_{0}-\beta+\mathrm{i}_{2}+\alpha_{1}\right)\right]
\end{aligned}
$$

Now, substituting, the values of $\mathrm{M}_{1}, \mathrm{M}_{2}, \mathrm{M}_{3}$ and other parameters as derived above in Eq. 7, the resultant dynamic active earth pressure can be obtained by searching the maximum value of $\mathrm{P}_{\mathrm{AE}}$. Since $\omega_{0}$ is unknown, the iteration process starts with an assumed initial value of $\omega_{0}$ by using trial and error method. The iteration is performed until $\mathrm{P}_{\mathrm{AE}}$ attains the maximum value. The convergence and the accuracies of the analytical solution, thus, depend to a greater extent on the value of $\omega_{0}$.

Effect of the localized strain on failure surface: As mentioned elsehwere, the M-O method assumes that mobilization of the friction angle, $\phi$, along the failure surface (Fig. 7a) takes place simultaneously irrespective of the locations. However, $\left(\phi_{\mathrm{mob}}\right)$ attainment of the active state of backfill involves progressive deformation. This implies that the mobilized friction angle is progressive with different values of the friction angle at different locations of the failure surface, which are at different states of deformation. In the analysis and design of retaining structures, the effect of such localized deformation can be quite significant. Development of strain localization in the backfill of retaining wall was also confirmed by Uwabe and Moriya $^{[34]}$ through their shaking table experiments. Bolton and Steedman ${ }^{[38]}$ showed that the angle of shear resistance (internal friction) mobilized along the failure surface drops by about $17^{\circ}$ during the dynamic loading. 


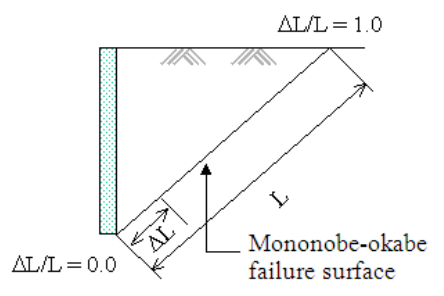

(a)

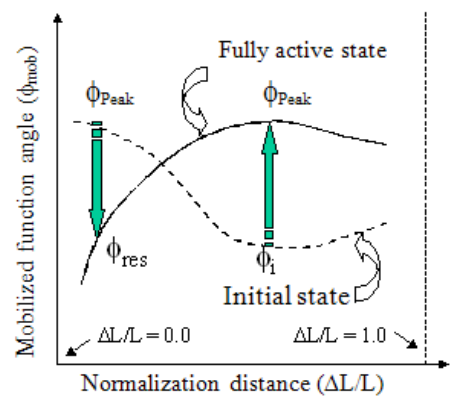

(b)

Fig. 7: Progressive deformation within the failure surface

On the other hand, from strain localization based numerical analyses of an experimental research on seismic earth pressure, Hazarika and Matsuzawa ${ }^{[39]}$ found that the variation of friction angle along the failure surface (Fig. 7a) depends on the state of deformation of the wall and the backfill. Such behavior of the mobilized friction angle $\left(\phi_{\mathrm{mob}}\right)$, is conceptually shown in Fig. 7b when the backfill transforms from an initial active state to the fully active state. It can be observed that when the backfill reaches the fully active state, at locations close to the base of the wall, mobilized values of the friction angle have already reached the residual state. Peak values, on the other hand, are mobilized somewhere else (close to the backfill surface). From Fig. 7, it can also be observed that at the same normalized distance, while the value of $\phi$ drops from the peak value $\left(\phi_{\text {peak }}\right)$ to a residual value $\left(\phi_{\text {res }}\right)$ at the lower locations (near the base), it increases from an initial value $\left(\phi_{\mathrm{i}}\right)$ to the peak value $\left(\phi_{\text {peak }}\right)$ at the upper locations (near the surface). Such localized variation of strength greatly influences the calculated values of seismic active earth pressure.

In order to incorporate the localized deformation behavior of the backfill, two different values ( $\phi_{\text {peak }}$ and $\phi_{\text {res }}$ ) of the angle of internal friction, $\phi$, were considered in the formulations that were derived in the preceding section. Following the trend in Fig. 7, it was assumed that the log spiral part (BD in Fig. 2) has the mobilized shear strength $\left(\phi_{\mathrm{mob}}\right)$, while the Rankine zone (ADC) maintains the peak strength $\left(\phi_{\text {peak }}\right)$. Therefore, in the calculation of the moment $M_{1}^{\prime}, \phi$ is replaced by $\phi_{\text {mob }}$ and while in the calculation of the moment $\mathrm{M}_{3}, \phi$ is replaced by $\phi_{\text {peak }}$. The mobilized shear strength, $\phi_{\text {mob }}$ can be evaluated using the concept of progressive index put forward by Rowe $\mathrm{e}^{[40]}$, which is defined as following:

$\mu_{\mathrm{p}}=\frac{\phi_{\text {peak }}-\phi_{\text {mob }}}{\phi_{\text {peak }}-\phi_{\text {res }}}$

Based on the model studies of dense sands, Rowe ${ }^{[40]}$ suggested that $\mu_{\mathrm{p}}$ at field scales could be taken as 0.4 for the active pressure and 0.8 for the passive pressure for practical design. It was claimed that these values were applicable to sands at intermediate densities as well. Using an appropriate value of $\mu_{\mathrm{p}}$, the various geometrical factors appearing in the formulations described in the preceding section were calculated that would yield the best curve fitting for the other strength parameters of the backfill soil.

\section{RESULTS}

In order to evaluate the accuracy of the proposed methodology, it was first applied to calculate and compare the experimental results of two model shaking table tests involving vertical retaining wall with horizontal backfill $\alpha_{1}=0, \beta=0$ ). One (Case I) is the experimental model of Ichihara and Matsuzawa ${ }^{[7]}$ and the other (Case II) is the experimental model of Ishibashi and Fang ${ }^{[8]}$.

Ichihara and Matsuzawa ${ }^{[7]}$ conducted a shaking table test using a large scale vibrating soil bin to estimate the active earth pressure as well as the at-rest pressure during earthquakes. The model wall (height $=55 \mathrm{~cm}$ ) used in the test could translate as well as rotate about its base. Dry Toyoura sand was used as the backfill material. Earth pressures were calculated from the readings of the three load cells attached to the wall. In that experimental model, the active earth pressure during earthquake was calculated by defining the active state as the stage when the angle of friction between the wall and the backfill reaches its maximum value.

Ishibashi and $\mathrm{Fang}^{[8]}$ investigated the dynamic active earth pressure against a rigid retaining structure using a model shaking table experiment. In that experiment, $1 \mathrm{~m}$ high retaining wall was used that could undergo various modes of wall movement such as translation, rotation about the base and rotation about the top ${ }^{[39]}$. Ottawa silica sand was used as the backfill material. Dynamic earth pressures were measured using earth pressure cells attached to the model wall. 
Defining the dynamic active state as the stage where no appreciable stress change was observed after a certain amount of wall rotation, Ishibashi and Fang ${ }^{[8]}$ found that the dynamic active earth pressure is strongly influenced by the wall movement modes at a low level of acceleration, while the inertial body effect becomes dominant at the higher acceleration level.

The following backfill properties were used in each case. For Case I (Toyoura sand): $\phi_{\text {peak }}=51^{\circ}$, $\phi_{\text {res }}=30^{\circ}$ and for Case II (Ottawa silica sand): $\phi_{\text {peak }}=41^{\circ}, \phi_{\text {pes }}=20^{\circ}$. The wall friction $(\delta)$ values in each case were assumed to be $2 \phi_{\text {peak }} / 3$ For Case I, based on plane strain tests it was reported ${ }^{[7]}$ that $\phi_{\text {peak }}=42^{\circ}$. However, in the present analysis $\phi_{\text {peak }}=51^{\circ}$ was adopted to account for the low confining stress. This high value at low confining stress was obtained from the extrapolation of test data at various high confining stresses.

Seismic active earth pressures prediction: Coefficients of the seismic active thrust $\left(\mathrm{K}_{\mathrm{AE}}\right)$ at the maximum inertia force (i.e. when the inertia force acts towards the wall), with increasing acceleration amplitudes, are shown in Fig. 8 and 9 for the Case I and Case II respectively. Values of $\mathrm{K}_{\mathrm{AE}}$ are back calculated by using the values of $\mathrm{P}_{\mathrm{AE}}$ obtained from the analysis. It can be seen that the proposed method could predict the experimental trend (both qualitatively and quantitatively) with reasonable credibility. The $\mathrm{M}-\mathrm{O}$ method, on the other hand, yields only lower bound values. Strain localization within the backfill can be partly held responsible for such underestimation by the M-O method.

Failure domain prediction: Referring to Fig. 2, the failure domain predicted by the $\mathrm{M}-\mathrm{O}$ theory is given by the following equation:

$\frac{\mathrm{AC}}{\mathrm{H}}=\frac{\frac{1+\tan \alpha_{1} \tan \beta}{\tan \alpha-\tan \beta}+\tan \alpha_{1}}{\cos \beta}$

In the above equation, the angle $\alpha$ can be obtained from the following equation:

$$
\begin{aligned}
\cot (\alpha-\beta)= & \sqrt{\frac{\cos \left(\alpha_{1}+\delta+\theta_{0}\right) \sin (\varphi+\delta)}{\cos \left(\alpha_{1}-\beta\right) \sin \left(\varphi-\beta-\theta_{0}\right)}} \\
& -\tan \left(\alpha_{1}+\varphi+\delta-\beta\right)
\end{aligned}
$$

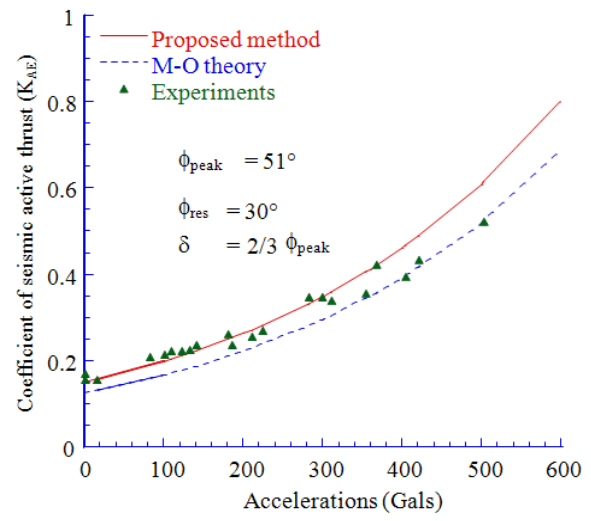

Fig. 8: Seismic coefficients at the maximum inertia force $^{[7,32]}$

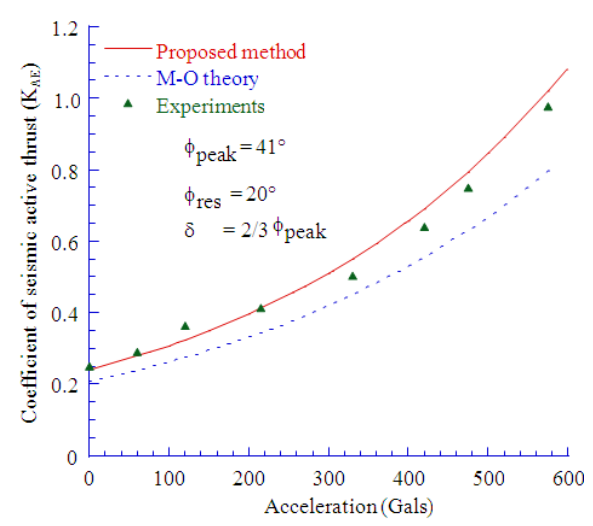

Fig. 9: Seismic coefficients at the maximum inertia force $^{[8]}$

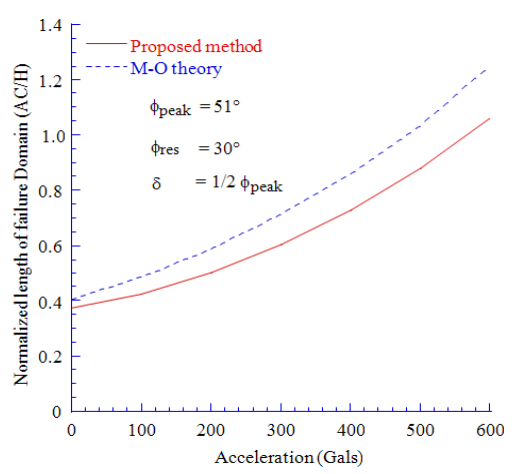

Fig. 10: Predicted domain (at maximum inertia force) of the active failure zone

In Fig. 10 the predicted failure domains $\mathrm{AC}$ (normalized by the wall height, $\mathrm{H}$ ) for the experimental model of Ichihara and Matsuzawa ${ }^{[7]}$ are compared with those obtained using the $\mathrm{M}-\mathrm{O}$ method. Comparison 
shows that the proposed method predicts much smaller failure domain than the M-O method. Calculated results have also demonstrated that, the differences between the values predicted by the proposed method and the M-O method widen, when the acceleration level exceeds 200 Gal. Therefore, it can be inferred that under intense earthquake motion (as required by the dual level approach of the performance-based design), the results predicted by the $\mathrm{M}-\mathrm{O}$ method becomes unreliable and can lead to an uneconomic design. It is to be noted that smaller failure domain will normally mean lesser pressure. However, when strain localization takes place it increases the pressure. Such increment of pressure cannot be taken into account if the M-O method is used. This may be the reason why in Fig. 8 the calculated values show higher values of the pressure.

Application to other wall types and backfill: In the above section, only ideal cases of model retaining walls (vertical back face and horizontal ground surface) were considered. In order to verify the applicability of the proposed methodology to actual retaining structures, a new set of calculations were made for walls with various back face angle $\left(\alpha_{1}\right)$ and ground surface inclination $(\beta)$.

Influence of backfill inclination and wall type on seismic active earth pressure: The coefficients of seismic active earth pressures were calculated for various values of backfill inclinations $\beta=0^{\circ}, 5_{.1^{\circ}}{ }^{\circ}, 15^{\circ}$ ) for three different types of wall (Case A, Case B and Case C). Case $\mathrm{A}\left(\alpha_{1}=0^{\circ}\right)$ represents a vertical retaining wall, Case B $\left(\alpha_{1}=20^{\circ}\right)$ represents a retaining wall with positive back face inclination angle and Case $\mathrm{C}$ $\left(\alpha_{1}=-20^{\circ}\right)$ represents a retaining wall with negative back face inclination angle(Leaning-type retaining wall). Material properties of the backfill chosen were: $\phi_{\text {peak }}=40^{\circ}, \phi_{\text {res }}=20^{\circ}$. The wall friction angle was taken as $\delta=\phi_{\text {peak }} / 2$.

Figure 11a-c show the horizontal coefficient of seismic active earth pressure as a function of horizontal acceleration coefficient, $\mathrm{k}_{\mathrm{h}}$ at various backfill inclinations for the Case A, Case B and Case C respectively. It can be observed that with increasing backfill inclination $\beta$, in all the three cases, the coefficients of the seismic active earth pressure increase. On the contrary, the M-O method underestimates the values of the coefficients; the higher is the acceleration, the greater is the underestimation. Therefore, there is a high degree of risk involved when using the M-O method for the earthquake resistant design of structures especially under intense ground motion (e.g., L2 earthquake motion in performancebased design). It can also be observed from these results that, for the same backfill inclination angle $\beta$, wall with positive back inclination (Case B) experiences the largest seismic active earth pressure, while wall with negative back inclination (Case C) experiences the smallest seismic active earth pressure. A different methodology for the calculation of static and seismic active earth pressures has also been presented by Choudhury and Singh ${ }^{[41]}$ for positively inclined rigid wall with inclined backfill surface (Fig. 11b).

Influence of backfill inclination and wall type on failure domain: Figure 12a-c show the failure domains predicted by the proposed methodology at various backfill inclinations for Case A, Case B and Case C respectively. It can be observed that with increasing backfill inclination $\beta$, the domains of the failure zone expand. At low acceleration levels, failure domains do not differ significantly even with increasing backfill inclinations.

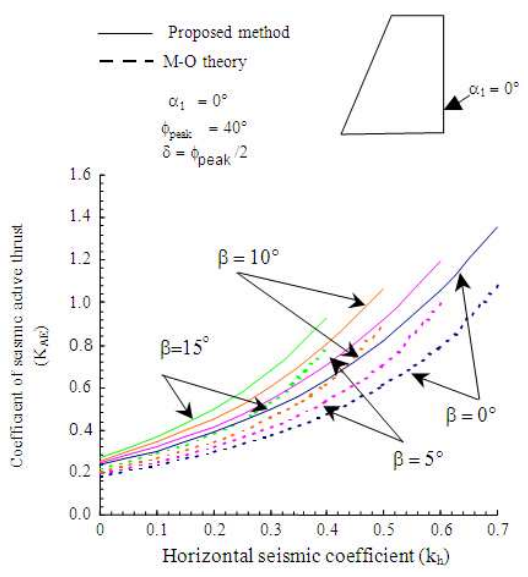

(a)

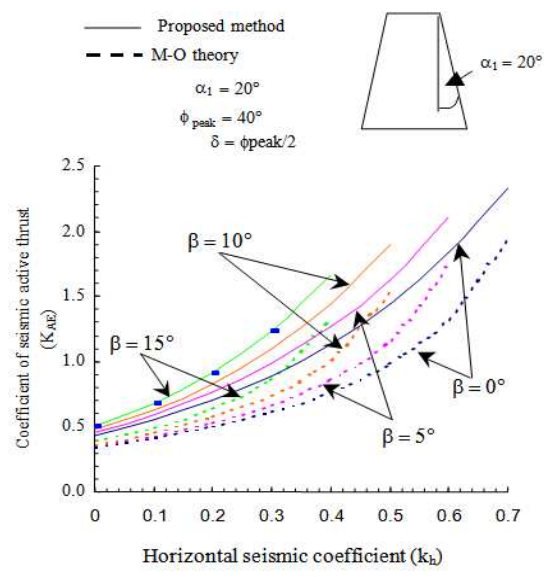

(b)

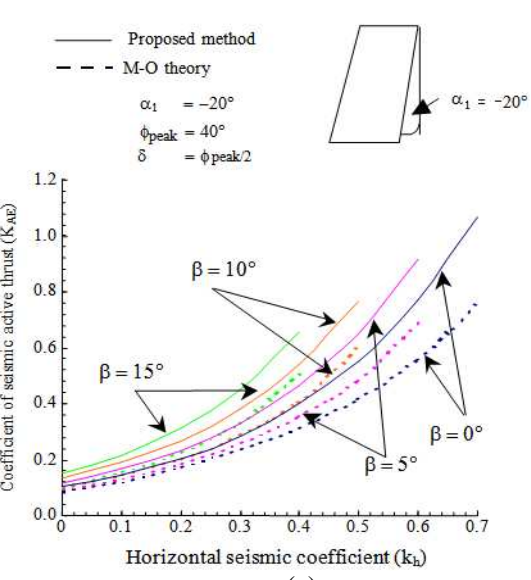

(c)

Fig. 11: Seismic coefficients for different types of wall 


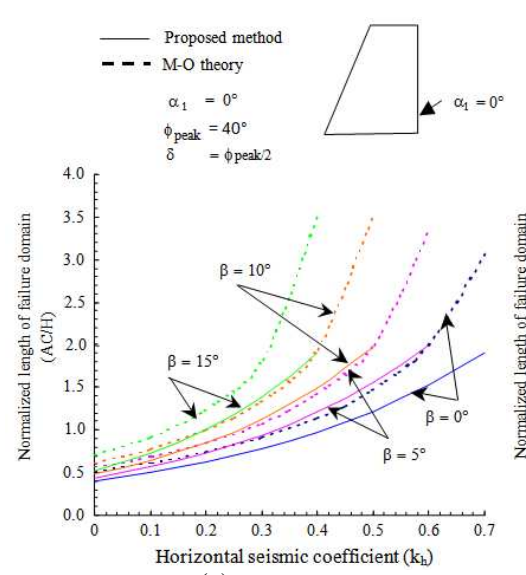

(a)

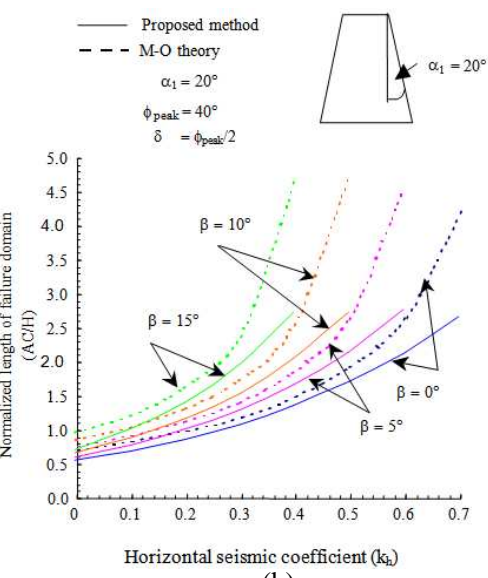

(b)

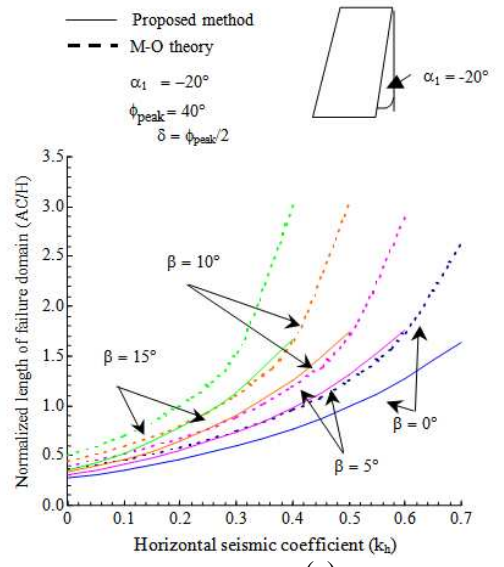

(c)

Fig. 12: Failure domain prediction for different types of wall; (a): Case A; (b): Case B; (c): Case C

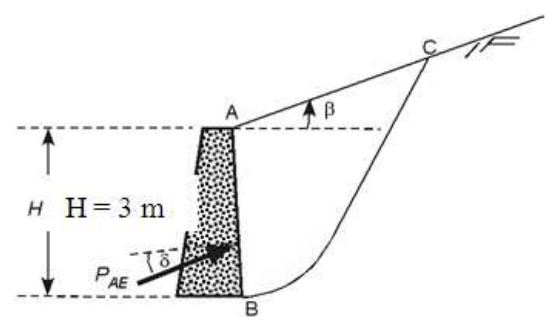

Fig. 13: Backfill with $\phi=40^{\circ}$

However, as the acceleration levels increase, the differences between the predicted values widen. Once again it can be observed that, in all the three cases, the $\mathrm{M}-\mathrm{O}$ method overestimates the failure domain. At high acceleration amplitude, over estimation can be as large as 1.5 times that of the proposed methodology. Failure domains predicted by the M-O method follow exponential curves, which show a sudden jump when horizontal acceleration coefficient exceeds 0.2. Therefore, recommendation of Noda et al. ${ }^{[36]}$ to modify the value of $k_{h}$ beyond $200 \mathrm{Gal}$, sounds practical. It is noteworthy that prediction of higher domain of the failure zone may lead to higher cost of construction, as large volume of soil are to be improved in such cases to mitigate any potential hazard during earthquakes.

\section{DISCUSSION}

Calculations were also performed for a retaining wall of height $3 \mathrm{~m}$ supporting dry and sandy backfill. Table 1 and 2 show the failure domains predicted by the present methodology for the shown configuration of the wall (Fig. 13 and 14) for a backfill with two different angles of internal friction $\left(\phi=40^{\circ}\right.$ and $\left.50^{\circ}\right)$, wall friction angles and backfill inclinations. In the earthquake resistant design of retaining structures, such tabulated values are expected to be of practical relevance.

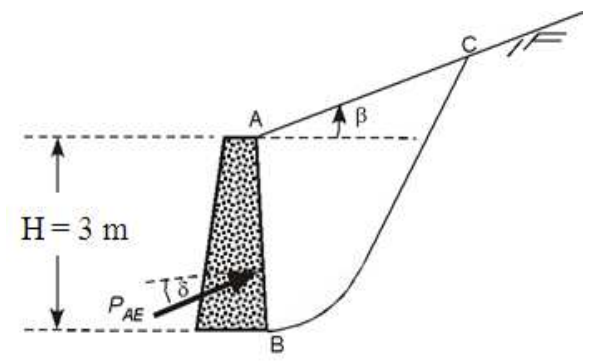

Fig. 13 b: Backfill with $\phi=50^{\circ}$

Table 1: For backfill with $\mathrm{c}=0 \mathrm{kPa} ; \phi=40^{\circ}$ Inclination of backface of the wall, $\alpha=+20^{\circ}$

\begin{tabular}{|c|c|c|c|c|c|}
\hline $\mathrm{d}$ & $\mathrm{b} / \mathrm{Kh}$ & 0 & $1 / 8 \phi$ & $1 / 4 \phi$ & $3 / 8 \phi$ \\
\hline \multirow[t]{8}{*}{$1 / 3 \phi$} & 0.0 & 0.55 & 0.61 & 0.67 & 0.73 \\
\hline & 0.1 & 0.68 & 0.77 & 0.86 & 1.00 \\
\hline & 0.2 & 0.84 & 0.97 & 1.11 & 1.37 \\
\hline & 0.3 & 1.04 & 1.23 & 1.43 & 1.87 \\
\hline & 0.4 & 1.29 & 1.55 & 1.84 & 2.55 \\
\hline & 0.5 & 1.60 & 1.96 & 2.37 & \\
\hline & 0.6 & 1.97 & 2.47 & & \\
\hline & 0.7 & 2.44 & & & \\
\hline \multirow[t]{8}{*}{$1 / 2 \phi$} & 0.0 & 0.58 & 0.64 & 0.72 & 0.80 \\
\hline & 0.1 & 0.70 & 0.79 & 0.92 & 1.08 \\
\hline & 0.2 & 0.85 & 0.98 & 1.17 & 1.47 \\
\hline & 0.3 & 1.03 & 1.21 & 1.49 & 1.99 \\
\hline & 0.4 & 1.26 & 1.50 & 1.90 & 2.69 \\
\hline & 0.5 & 1.52 & 1.86 & 2.43 & \\
\hline & 0.6 & 1.85 & 2.30 & & \\
\hline & 0.7 & 2.24 & & & \\
\hline \multirow[t]{8}{*}{$2 / 3 \phi$} & 0.0 & 0.61 & 0.68 & 0.74 & 0.84 \\
\hline & 0.1 & 0.75 & 0.86 & 0.97 & 1.15 \\
\hline & 0.2 & 0.93 & 1.08 & 1.28 & 1.57 \\
\hline & 0.3 & 1.16 & 1.37 & 1.68 & 2.15 \\
\hline & 0.4 & 1.43 & 1.73 & 2.21 & 2.94 \\
\hline & 0.5 & 1.77 & 2.18 & 2.90 & \\
\hline & 0.6 & 2.19 & 2.75 & & \\
\hline & 0.7 & 2.71 & & & \\
\hline
\end{tabular}


Am. J. Engg. \& Applied Sci., 2 (3): 544-558, 2009

Table 2: For backfill with $\mathrm{c}=0 \mathrm{kPa} ; \phi=50^{\circ}$ Inclination of backface of the wall, $\alpha=+20$

\begin{tabular}{llllll}
\hline $\mathrm{d}$ & $\mathrm{b} / \mathrm{Kh}$ & 0 & $1 / 8 \phi$ & $1 / 4 \phi$ & $3 / 8 \phi$ \\
\hline $1 / 3 \phi$ & 0.0 & 0.4 & 0.45 & 0.49 & 0.54 \\
& 0.1 & 0.5 & 0.56 & 0.63 & 0.73 \\
& 0.2 & 0.62 & 0.71 & 0.81 & 1.00 \\
& 0.3 & 0.76 & 0.90 & 1.05 & 1.37 \\
& 0.4 & 0.95 & 1.14 & 1.35 & 1.87 \\
& 0.5 & 1.17 & 1.43 & 1.74 & \\
& 0.6 & 1.45 & 1.81 & & \\
$1 / 2 \phi$ & 0.7 & 1.79 & & & \\
& 0.0 & 0.43 & 0.47 & 0.53 & 0.59 \\
& 0.1 & 0.52 & 0.58 & 0.67 & 0.79 \\
& 0.2 & 0.63 & 0.72 & 0.86 & 1.08 \\
& 0.3 & 0.76 & 0.89 & 1.09 & 1.46 \\
& 0.4 & 0.92 & 1.10 & 1.40 & 1.97 \\
& 0.5 & 1.12 & 1.36 & 1.78 & \\
& 0.6 & 1.35 & 1.68 & & \\
$2 / 3 \phi$ & 0.7 & 1.64 & & & \\
& 0.0 & 0.45 & 0.50 & 0.54 & 0.62 \\
& 0.1 & 0.55 & 0.63 & 0.71 & 0.84 \\
& 0.2 & 0.68 & 0.79 & 0.94 & 1.15 \\
& 0.3 & 0.85 & 1.00 & 1.23 & 1.58 \\
& 0.4 & 1.05 & 1.27 & 1.62 & 2.15 \\
& 0.5 & 1.30 & 1.60 & 2.12 & \\
& 0.6 & 1.61 & 2.02 & & \\
& 0.7 & 1.99 & & & \\
\hline
\end{tabular}

\section{CONCLUSION}

In the design of important structures in a seismically active region, it is essential to estimate correctly the earth pressures during earthquake. There is a trend among the geotechnical professionals to utilize the Mononobe-Okabe method in design without understanding the implications of various assumptions used in the theory. It is safer to use that method only under limited conditions and also with high values of the factors of safety. Design based on the MononobeOkabe method can be precarious, when seismic motion is too intense. With the introduction of the performance-based design in many design codes throughout the world, blind use of the method, thus, needs careful consideration.

On the other hand, strain localization within backfill increases the magnitude of the active pressure. Therefore, it is also important to incorporate mobilized value of the angle of internal friction in a formulation so that the influence of such progressive deformation phenomenon is taken care of. In addition, the planar assumption of the failure surface in the M-O theory underestimates the resulting calculation of the earth pressure during earthquakes. In order to predict accurately the seismic earth pressure by analytical means, it is also, necessary to introduce a composite type failure surface in the formulation. The influences of these two factors on the seismic active earth pressure were verified in this research by analytical means.
Results obtained from this analytical study have shown that the Mononobe-Okabe method underestimates the seismic active earth pressure and overestimates the failure domain, especially at the higher levels of seismic excitation. Since, during earthquakes retaining structures are mostly damaged due to increase of active pressure, accurate prediction of the active failure zone with increasing acceleration, assumes significant importance when other structures are to be built in the backfill. Overestimation of failure zone (as has been the case with the Mononobe-Okabe method and the other method based on that method) may lead to the unnecessary cost of construction, especially when ground improvement measures are necessary.

With the advent of high-speed personnel computer and cutting edge technology of the present era, engineers and researchers no longer need to be confined to conservative and simplified methods such as the Mononobe-Okabe method for the seismic earth pressure calculations. The calculation method proposed here, thereby, can have enormous practical implications, especially in the earthquake resistant design of urban amenities and infrastructures.

\section{ACKNOWLEDGEMENT}

The researchers gratefully acknowledges Prof. Isao Ishibashi, Old Dominion University, Virginia, USA for his invaluable suggestions on the improvement of the contents and clarity of the study.

\section{REFERENCES}

1. Nazarian, H.N. and A.H. Hadjian, 1979. Earthquake-induced lateral soil pressures on structures. J. Geotech. Eng., ASCE., 105: 1049-1066. http://www.pubs.asce.org/WWWdisplay.cgi?50148 05

2. Ishihara, K., 1997. Geotechnical aspects of the 1995 Kobe earthquake, Terzaghi orientation. Proceeding of the14th International Conference of International Society of Soil Mechanics and Geotechnical Engineering, Hamburg, Germany, ICSMFE.

3. PIANC 2001. Seismic Design Guidelines for Port Structures. The Netherlands: Balkema, ISBN: 9026518188, pp: 500.

4. Tatsuoka, F., M. Tateyama and J. Koseki, 1996. Performance of soil retaining walls for railway embankments. Hyogoken-Nambu Earthquake, 1: 311-324.

http://cat.inist.fr/?aModele $=$ afficheN\&cpsidt $=2546348$ 
5. Mononobe, N. and H. Matsuo, 1929. On the determination of earth pressure during the earthquake. Proceeding of the World Engineering Conference, pp: 177-185.

6. Okabe, S., 1924. General theory on earth pressure and seismic stability of retaining walls and dams. J. Japanese Soc. Civil Eng., 10: 1277-1323. http://nisee.berkeley.edu/elibrary/Text/200606309

7. Ichihara, M. and H. Matsuzawa, 1973. Earth pressure during earthquake. Soil Found., 13: 75-86. http://ci.nii.ac.jp/naid/110003913220/

8. Ishibashi, I. and Y.S. Fang, 1987. Dynamic earth pressures with different wall movement modes. Soil Found., 27: 11-22. http://ci.nii.ac.jp/naid/110003985189/

9. Matsuzawa, H., I. Ishibashi and M. Kawamura, 1985. Earthquake-induced lateral soil pressures on structures. J. Geotech. Eng. ASCE., 111: 1161-1176.

10. Richard, R. and D. Elms, 1979. Seismic behavior of gravity retaining walls. J. Geotech. Eng. ASCE., 105: 449-464. http://www.pubs.asce.org/WWWdisplay.cgi?5014496

11. Seed, H.B. and R.V. Whitman, 1970. Design of earth retaining structures for dynamic loads. Proceeding of the Special Conference on Lateral Stress, Ground Displacement and Earth Retaining Structures, Sept. 25-25, Ithaca, New York, pp: 103-147. http://www.seaintarchive.org/group/seaint/mailarch ive/2000c/msg02306.html

12. Sherif, M.A., Y.S. Fang and R.I. Sherif, 1984. $\mathrm{K}_{\mathrm{A}}$ and $\mathrm{K}_{0}$ behind rotating and non-yielding walls. J. Geotech. Eng. ASCE., 110: 41-56.

13. Sherif, M.A., I. Ishibashi and C.D. Lee, 1982. Earth pressures against rigid retaining walls. J. Geotech. Eng. ASCE., 108: 679-695. http://www.pubs.asce.org/WWWdisplay.cgi?8200481

14. Steedman, R.S. and X. Zeng, 1990. Seismic response of waterfront retaining walls. Proceedings of the International Conference on Design and Performance of Earth Retaining Structures, June 1821, Ithaca NY, ASCE Geotechnical Special Publication, No. 25, pp: 872-886.

15. Whitman, R.V., 1990. Seismic design and behavior of gravity retaining walls. Proceedings of the International Conference on Design and Performance of Earth Retaining Structures, (DPERS'90), ASCE., New York, pp: 817-842. http://cedb.asce.org/cgi/WWWdisplaybn.cgi?0872 627616

16. Whitman, R.V., 1991. Seismic design of earth retaining structures. Proceeding of the 2nd International Conference on Recent Advances in Geotechnical Earthquake Engineering and Soil Dynamics, Missouri, University of Missouri, Rolla, USA.
17. Veletsos, A. and A.H. Younan, 1994. Dynamic soil pressure on rigid vertical walls. Earthquake Eng. Soil Dyn., 23: 275-301.

18. Zeng, X. and R.S. Steedman, 2000. Rotating block method for seismic displacement of gravity retaining walls. J. Geotech. Environ. Eng. ASCE., 106: 709-717. http://cat.inist.fr/?aModele=afficheN\&cpsidt=1431819

19. Ebeling, R.M. and E.E. Morrison, 1992. The seismic design of waterfront retaining structures. US Army Corps of Engineers, Technical Report ITL-92-11/NCEL TR-939.

http://www.ntis.gov/search/product.aspx?abbr=AD A262963

20. Ministry of Transport, 1999. Design standard for port and harbor facilities and commentaries. Japan Port and Harbor Association (In Japanese), Japan, Tokyo.

21. Sugano, T., Y. Nozue, T. Tanaka, A. Nozu, E. Kohama, H. Hazarika and I. Motono, 2007. Damage to Port Facilities by the 2005 west off fukuoka prefecture earthquake. Technical Note, Port and Airport Research Institute, Yokosuka, Japan.

22. Towhata, I., A. Ghalandarzadeh, K.P. Sundarraj and V. Monge, W. 1996. Dynamic failures of subsoils observed in waterfront area. Soils Found., 1: 149-160. http://cat.inist.fr/?aModele $=$ afficheN\&cpsidt $=2546$ 703

23. Ostadan, F., 2005. Seismic soil pressure for building walls-an updated approach. Proceeding of the International Conference on Soil Dynamics and Earthquake Engineering, (SDEE'05), Berkley, USA., $\quad$ pp: 7-10. http://cat.inist.fr/?aModele $=$ afficheN\&cpsidt $=17122822$

24. ISO., 2004. Base for design of structures-Seismic actions for geotechnical works. Technical Committee ISO/TC98, ISO/CD 23469 Final Draft.

25. Koseki, J., F. Tatsuoka, Y. Munaf, M. Tateyama and K. Kojima, 1998. A modified procedure to evaluate active earth pressure at high seismic loads. Special Issue Soil. Found., 2: 209-216. http://soil.iis.utokyo.ac.jp/HP2007/Lecture/Koseki-3paper.pdf

26. Zhang, J.M. and D. Li, 2001. Seismic active earth pressure considering the effect of strain localization. Proceedings of the 4th International Conference on Recent Advances in Geotechnical Earthquake Engineering and Soil Dynamics, California, Editor: S. Prakash, University of Missouri, Rolla, USA.

27. Nakamura, S., 2006. Reexamination of MononobeOkabe theory of gravity retaining walls using centrifuge model tests, Soil. Found., 46: 135-146. http://ci.nii.ac.jp/naid/110006151464/ 
28. Fang, Y.S. and T.J. Chen, 1995. Modification of Mononobe-Okabe theory. Geotechnique, 45: 165-167. http://cat.inist.fr/?aModele $=$ afficheN\&cpsidt $=344470$ 1

29. Chang, M.F. and W.F. Chen, 1982. Lateral earth pressure on rigid retaining walls subject to earthquake forces. Solid Mech. Arch., 7: 315-362.

30. Chen, W.F. and J.L. Rosenfarb, 1973. Limit analysis solutions of earth pressure problems. Soil Found., 13: 45-60. http://ci.nii.ac.jp/naid/110003913218/

31. SEAOC., 1995. Performance Based Seismic Engineering of Buildings. Structural Engineers Association of California, Sacramento, California, Vision 2000 Report, USA.

32. Ichihara, M., N. Mori, S. Nakane and I. Hirano, 1973. Passive earth pressure coefficient during earthquake. Memoirs of the Faculty of Engineering, Nagoya University, Nagoya, Japan, 25: 129-179.

33. Soubra, A.M. and B. Macuh, 2001. Seismic active and passive earth pressures on rigid retaining structures by a kinematical approach. Proceeding of the 4th International Conference on Recent Advances in Geotechnical Earthquake Engineering and Soil Dynamics, San Diego, USA.

34. Uwabe and Moriya, 1988. Shaking table model tests of sliding gravity-type retaining walls during earthquake. Proceedings of the 9th WCEE, Kyoto, Japan, pp: 685-690.

35. Sokolovski, V.V., 1960. Statics of Soil Media. Butterworth Scientific Publications, pp: 237.
36. Noda, S., T. Uwabe and T. Chiba, 1975. Relation between seismic coefficient and ground acceleration for gravity quay wall. Rep. Port Harbor Res. Inst., 14: 67-111.

37. Matsuo, M. and K. Itabashi, 1984. Study on aseismicity evaluation of slopes and earth structures. J. JSCE., 352: 139-147.

38. Bolton, M.D. and R.S. Steedman, 1985. Modeling the seismic resistance of retaining structures. Proceeding of the 11th International Conference of International Society of Soil Mechanics and Geotechnical Engineering, (SSMGE'85), Cambridge, pp: 1845-1848. http://wwwciv.eng.cam.ac.uk/geotech_new/people/bolton/mdb _pub/13_Proc_ICSMFE_1985_vol4_1845_1848.p df

39. Hazarika, H. and H. Matsuzawa, 1997. Coupled shear band method and its application to the seismic earth pressure problems. Soil Found., 37: 65-77.

http://cat.inist.fr/?aModele=afficheN\&cpsidt $=2074$ 898

40. Rowe, P.W., 1969. Progressive failure and strength of a soil mass. Proceedings of the 7 th International Conference on Soil Mechanics and Foundation Engineering, Mexico, 1: 34-49.

41. Choudhury, D. and S. Singh, 2006. New approach for estimation of static and seismic active earth pressure. Geotech. Geol. Eng., 24: 117-127. DOI: 10.1007/s10706-004-2366-x 